\title{
Adrenomedullin-RAMP2 System Is Crucially Involved in Retinal Angiogenesis
}

\author{
Yasuhiro Iesato, ${ }^{* \dagger}$ Yuichi Toriyama, ${ }^{* \dagger}$ Takayuki Sakurai, ${ }^{*}$ Akiko Kamiyoshi, ${ }^{*}$ Yuka Ichikawa-Shindo, ${ }^{*}$ Hisaka Kawate, ${ }^{*}$ \\ Takahiro Yoshizawa, ${ }^{*}$ Teruhide Koyama, ${ }^{*}$ Ryuichi Uetake, ${ }^{*}$ Lei Yang, ${ }^{*}$ Akihiro Yamauchi, ${ }^{*}$ Megumu Tanaka, ${ }^{*}$ Kyoko Igarashi, \\ Toshinori Murata, ${ }^{\dagger}$ and Takayuki Shindo*
}

From the Department of Cardiovascular Research, ${ }^{*}$ Shinshu University Graduate School of Medicine, Matsumoto; and the Department of Ophthalmology, ${ }^{\dagger}$ Shinshu University School of Medicine, Matsumoto, Japan

Accepted for publication

February 4, 2013.

Address correspondence to Takayuki Shindo, M.D., Ph.D., Department of Cardiovascular Research, Shinshu University Graduate School of Medicine, 3-1-1 Asahi, Matsumoto 3908621, Japan. E-mail: tshindo@ shinshu-u.ac.jp.

\begin{abstract}
Adrenomedullin (ADM) is an endogenous peptide first identified as a strong vasodilating molecule. We previously showed that in mice, homozygous knockout of $\mathrm{ADM}\left(\mathrm{ADM}^{-/-}\right)$or its receptor regulating protein, RAMP2 $\left(\mathrm{RAMP}^{-}{ }^{-}-\right.$), is embryonically lethal due to abnormal vascular development, thereby demonstrating the importance of ADM and its receptor signaling to vascular development. ADM expression in the retina is strongly induced by ischemia; however, its role in retinal pathophysiology remains unknown. Here, we analyzed oxygen-induced retinopathy (OIR) using heterozygous ADM and RAMP2 knockout mice models $\left(A D M^{+/-}\right.$or $R A M P 2^{+/-}$, respectively). In addition, we analyzed the role of the ADM-RAMP2 system during earlier stages of retinal angiogenesis using an inducible endothelial cellspecific RAMP2 knockout mouse line (DI-E-RAMP2 ${ }^{-/-}$). Finally, we assessed the ability of antibodyinduced ADM blockade to control pathological retinal angiogenesis in OIR. In OIR, neovascular tufts, avascular zones, and hypoxic areas were all smaller in $\mathrm{ADM}^{+/-}$retinas compared with wild-type mice. $A D M^{+/-}$retinas also exhibited reduced levels of VEGF and eNOS expression. DI-E-RAMP2 ${ }^{-/-}$showed abnormal retinal vascular patterns in the early stages of development. However, ADM enhanced the proliferation and migration of retinal endothelial cells. Finally, we found intravitreal injection of antiADM antibody reduced pathological retinal angiogenesis. In conclusion, the ADM-RAMP2 system is crucially involved in retinal angiogenesis. ADM and its receptor system are potential therapeutic targets for controlling pathological retinal angiogenesis. (Am J Pathol 2013, 182: 2380-2390; http:// dx.doi.org/10.1016/j.ajpath.2013.02.015)
\end{abstract}

Pathological retinal angiogenesis plays a key role in various retinal diseases, including diabetic retinopathy (DR), retinal vein occlusion, and retinopathy of prematurity. Retinal ischemia is thought to be a common precursor to pathological retinal angiogenesis, and ischemia-induced overexpression of vascular endothelial growth factor (VEGF) is one of the major causes of the resultant abnormal vessel growth. Intravitreal anti-VEGF antibody (bevacizumab or ranibizumab) administration targeting angiogenesis and increases in vessel permeability is widely used to treat exudative age-related macular degeneration, ${ }^{1} \mathrm{DR},{ }^{2}$ retinal vein occlusion, ${ }^{3}$ and retinopathy of prematurity. ${ }^{4}$ However, this approach has several associated drawbacks. One is the recurrence of macular edema; another is tachyphylaxis, which can occur after long-term anti-VEGF administration. ${ }^{5,6}$ Therefore, other therapeutic targets to control pathological angiogenesis are greatly needed.

Adrenomedullin (ADM) is a vasodilating polypeptide originally isolated from human pheochromocytoma, ${ }^{7}$ though

Supported by the Funding Program for Next Generation World-Leading Researchers from the Cabinet Office, Government of Japan; JSPS KAKENHI grant number 23390400 (T.M.); PRESTO of the Japan Science and Technology Agency (JST) (T.S.); A-STEP of the JST; a grant-in-aid for scientific research from the Ministry of Education, Culture, Sports, Science and Technology (T.S.); a research grant for cardiovascular disease from the National Cardiovascular Center; and Research Grants from the Mitsui Life Social Welfare Foundation, Takeda Science Foundation, Kanzawa Medical Research Foundation, Public Trust Fund for the Promotion of Surgery, Suzuken Memorial Foundation, Japan Heart Foundation research grant, the Naito Foundation, the SENSHIN Medical Research Foundation, and the NOVARTIS Foundation (Japan) for the Promotion of Science (T.S.). 
it is now known to be widely distributed in numerous tissues and organs and to exert a variety of physiological effects in addition to vasodilatation. Expression of ADM is upregulated under ischemic conditions. ${ }^{8-10}$ Furthermore, we previously showed that homozygous ADM knockout (KO) mice $\left(A D M^{-/}\right)$die in utero due to lethally abnormal vascular development; that ADM also possesses angiogenic activity; and that ADM exerts its angiogenic effects, not only during development, but also in adulthood in regions experiencing ischemia. ${ }^{11,12}$ The main body of the ADM receptor is calcitonin receptor-like receptor (CLR), a seven-transmembrane domain $\mathrm{G}$ protein-coupled receptor (GPCR). CLR associates with one of the three subtypes of receptor activitymodifying protein (RAMP), which determines the affinity of CLR for its ligands. ${ }^{13,14} \mathrm{We}$ also showed that homozygous RAMP2KO $\left(R A M P 2^{-/-}\right)$is lethal, with a phenotype similar to that of $A D M^{-/-}$, suggesting the ADM-RAMP2 system is specifically involved in vascular development. ${ }^{15}$

Expression of ADM has been detected in the eye. In earlier reports, ADM was shown to act as a vasodilator in the retinal arteries and to increase choroidal blood flow and ophthalmic arterial flow velocity. ${ }^{16,17}$ In addition, peripheral administration of ADM causes dose-dependent conjunctival hyperemia in rabbits. ${ }^{18}$ ADM also lowers intraocular pressure ${ }^{19}$ and relaxes iris sphincter smooth muscle via a cAMP-dependent pathway. ${ }^{20}$ Collectively, these data suggest that ADM could be involved in the pathophysiology of ocular diseases. Consistent with that idea, ADM levels are elevated in the vitreous fluid of patients with DR, ${ }^{21-23}$ suggesting ADM may be associated with pathological retinal angiogenesis.

Our initial aim in the present study was to clarify the pathophysiological roles of the ADM-RAMP2 system in the retina using an oxygen-induced retinopathy (OIR) model in heterozygous ADM and RAMP2 KO mice. We next generated an inducible endothelial cell-specific RAMP2 KO mouse to analyze the roles of the ADMRAMP2 system during the early stages of retinal vascular development. Finally, we assessed the ability of antibodyinduced ADM blockade to control pathological retinal angiogenesis.

\section{Materials and Methods}

\section{Animals}

Wild-type (WT) C57BL/6J mice were purchased from Charles River Laboratories Japan (Yokohama, Japan). $\mathrm{ADM}$ and RAMP2 $\mathrm{KO}$ mice were originally generated in our group. ${ }^{1,15}$ Because homozygous ADM and RAMP2 $\mathrm{KO}$ mice are embryonically lethal, we used heterozygous $\mathrm{KO}$ mice $\left(A D M^{+/-}, R A M P 2^{+/-}\right)$, in which ADM or RAMP2 expression is reduced to half that seen in WT mice.

To generate inducible vascular endothelial cell-specific RAMP2 KO mice, we crossed a mouse line expressing tamoxifen-inducible Cre recombinase (Cre-ERT2) under the regulation of VE-Cadherin ${ }^{24}$ with floxed RAMP2 mice. Cre activation and gene deletion were induced by $1 \mathrm{mg} / \mathrm{mL}$ intragastric injections of tamoxifen (T5648; Sigma-Aldrich, St. Louis, MO). For analysis of P6 neonates, $50 \mu \mathrm{g}$ of tamoxifen was injected on three consecutive days (postnatal day [P] 1 to P3); for analysis of P11 neonates, $100 \mu \mathrm{g}$ of tamoxifen was injected on four consecutive days (P5 to P8). ${ }^{25}$ Control mice were injected with corn oil (SigmaAldrich) on P1 to P3 or P5 to P8.

All animal handling procedures were in accordance with a protocol approved by the ethics committee of Shinshu University School of Medicine. All experiments were performed in accordance with the Association for Research in Vision and Ophthalmology's Statement for the Use of Animals in Ophthalmic and Vision Research and our institutional guidelines.

\section{RNA Extraction and Quantitative Real-Time RT-PCR Analysis}

Mice were euthanized and retinas were removed on P17. Total RNA was extracted from each sample using Trizol Reagent (Invitrogen, Carlsbad, CA), after which the extracted RNA was treated with DNA-Free (Ambion, Austin, TX) to remove contaminating DNA, and $2-\mu \mathrm{g}$ samples were subjected to reverse transcription using a High Capacity cDNA Reverse Transcription Kit (Applied Biosystems, Carlsbad, CA). Quantitative real-time RT-PCR was performed using an Applied Biosystems 7300 real-time PCR System (Applied Biosystems) with SYBR Green (Toyobo, Osaka, Japan) or Realtime PCR Master Mix (Toyobo) and TaqMan probe (MBL International, Woburn, MA). Values were normalized to mouse GAPDH (TaqMan Pre-Developed Assay Reagents; Applied Biosystems). The primers and probes used are listed in Table 1.

\section{Western Blot Analysis}

Retinal tissue was lysed in an ice-cold RIPA Lysis Buffer System (Santa Cruz Biotechnology, Santa Cruz, CA) supplemented with PhosSTOP phosphatase inhibitor (Roche Applied Science, Indianapolis, IN) and then sonicated. Samples of the resultant lysate were subjected to SDSPAGE, and the resolved proteins were transferred to cellulose nitrate membranes (GE Healthcare, Chalfont St Giles, UK). After blocking in 5\% skim milk, the membranes were incubated with primary antibodies against $\beta$-tubulin (Santa Cruz Biotechnology), VEGF (Abcam, Cambridge, UK), endothelial nitric oxide synthase (eNOS) (Cell Signaling Technology, Danvers, MA), and phospho-eNOS (Ser1177; Cell Signaling Technology), followed by appropriate secondary antibodies (Santa Cruz Biotechnology). The bound antibodies were visualized using chemiluminescent horseradish peroxidase substrate (Millipore, Billerica, MA), and the chemiluminescence was analyzed using an ImageQuant LAS 4000 imager system (GE Healthcare). Levels of eNOS activation were determined based on the ratio of band 
Table 1 Primers and Probes Used for Quantitative Real-Time RT-PCR Analysis

\begin{tabular}{lll}
\hline Gene & & Sequence \\
\hline ADM & Forward & $5^{\prime}$-GGACACTGCAGGGCCAGAT-3' \\
& Reverse & $5^{\prime}$-GTAGTTCCCTCTTCCCACGACTTA-3' \\
RAMP2 & Forward & $5^{\prime}$-GCAGCCCACCTTCTCTGATC-3' \\
& Reverse & $5^{\prime}$-AACGGGATGAGGCAGATGG-3' \\
& Probe & $5^{\prime}$-CCCAGAGGATGTGCTCCTGGCCAT-3' \\
VEGF-A & Forward & $5^{\prime}$-CATCTTCAAGCCGTCCTGTGT-3' \\
& Reverse & $5^{\prime}$-CTCCAGGGCTTCATCGTTACA-3' \\
VEGFR1 & Forward & $5^{\prime}$-CAAGGACGGCTTTGCAGATC-3' \\
& Reverse & $5^{\prime}$-GCTCATGAATTTGAAAGCGTTTAC-3' \\
VEGFR2 & Forward & $5^{\prime}$-ACTGCAGTGATTGCCATGTTCT-3' \\
& Reverse & $5^{\prime}$-TCATTGGCCCGCTTAACG-3' \\
eNOS & Forward & $5^{\prime}$-AGGCACTGCTGAGCCGAGT-3' \\
& Reverse & $5^{\prime}$-TTCTCCAGTTGTTCCACAGCC-3' \\
EPO & Forward & $5^{\prime}$-CTACGTAGCCTCACTTCACTGCTT-3' \\
& Reverse & $5^{\prime}$-AGAGCTTGCAGAAAGTATCCACTGT-3' \\
Tie-2 & Forward & $5^{\prime}$-GGAACCTGACCTCGGTGCTA-3' \\
& Reverse & $5^{\prime}$-CTGCGCCTTGGTGTTGACT-3' \\
\hline
\end{tabular}

intensities after blotting with antibodies specific for the phosphorylated and unphosphorylated proteins. For quantification, Western blot images were captured and analyzed using Scion Image software version 4.0.3 (Scion Corporation, Frederick, MD).

\section{Analysis of Retinal Angiogenesis in the OIR Model}

Physiological and pathological retinal angiogenesis were quantified using previously reported protocols ${ }^{26}$ with slight modification. Briefly, on P17, the eyes were fixed in $4 \%$ paraformaldehyde for 1 hour at $4^{\circ} \mathrm{C}$ and then washed with PBS. Retinas were then isolated and stained overnight at $4^{\circ} \mathrm{C}$ with Alexa Fluor 594-conjugated Griffonia simplicifolia (formerly Bandeiraea simplicifolia) isolectin B4 (isolectin GS-IB4 from G. simplicifolia, Alexa Fluor 594 conjugate I21413; 1:200 dilution; Invitrogen) in 0.3\% PBS with Tween 20. After washing three times in PBS, the retinas were mounted whole onto microscope slides with the photoreceptor side down and embedded in fluorescent mounting medium (Dako, Glostrup, Denmark). Images of whole-mount retinas were taken at $\times 4$ magnification using a fluorescence microscope (BZ-9000; Keyence, Osaka, Japan). Avascular zones and neovascular tuft formation (represented as pathological angiogenesis) were quantified using digital imaging/photo editing software (Adobe Photoshop CS5 version 12.0.3; Adobe Systems, San Jose, CA).

Pathological angiogenesis was analyzed by counting the nuclei extending beyond the internal limiting membrane. The eyes were enucleated on P17 and fixed in 4\% paraformaldehyde for 24 hours, and then embedded in paraffin. Six sections were selected within $300 \mu \mathrm{m}$ of the optic nerve in serial $5-\mu \mathrm{m}$-thick sagittal sections of whole eyes and stained with $\mathrm{H} \& \mathrm{E}$, after which photomicrographs were taken (BZ-9000 microscope). All evaluations of retinal angiogenesis were done using double-blind methods.
Analysis of Retinal Ischemia in the OIR Model

Retinal ischemia was assessed using pimonidazole hydrochloride (Hypoxyprobe-1 [H-1]; Chemicon, Temecula, CA) according to the manufacturer's protocol. Briefly, mice were intraperitoneally injected with $50 \mathrm{mg} / \mathrm{kg} \mathrm{H}-190$ minutes before sacrifice. Detection of H-1-positive (hypoxic) areas was achieved through immunohistochemical analysis of retinal flat mounts after fixation in $4 \%$ paraformaldehyde using a primary antibody against the $\mathrm{H}-1$ probe (provided in the kit) and fluorescein isothiocyanate-conjugated secondary antibodies. Images were captured using a fluorescence microscope (BZ-9000) and subjected to morphometric analysis using Adobe Photoshop.

\section{Cell Culture}

The RF/6A135 chorioretinal endothelial cell (CREC) line was obtained from the Riken Cell Bank, Tsukuba, Japan, and cultured in RPMI 1640 medium (Invitrogen) supplemented with $10 \%$ fetal bovine serum (FBS).

The RAMP2-overexpressing (RAMP2O/E) endothelial cell line was created using EAhy926 endothelial cells, which is an immortal, clonally pure, human endothelial cell line (kindly provided by C.J. Edgell, University of North Carolina). Human RAMP2 cDNA was inserted into the cloning site of pcDNA3.1 $1^{+}$(Invitrogen), which was then transfected into EAhy926 cells to create the RAMP2 O/E cell line. ${ }^{15}$ EAhy926 cells transfected with empty pcDNA3. $1^{+}$vector served as control. EAhy926 endothelial cells were cultured in Dulbecco's modified Eagle's medium (Invitrogen) supplemented with 10\% FBS.

Human retinal endothelial cells (Cell Systems, Kirkland, WA) were cultured according to the manufacturer's protocol.

\section{Scratch-Wound Assay}

To determine whether ADM promotes CREC proliferation and migration, we performed scratch-wound assays as described by Liang et $\mathrm{al}^{27}$ with some modifications. CRECs were grown in 60-mm dishes with medium containing 10\% FBS until 90\% confluent, after which they were starved for 24 hours in $1 \%$ FBS + medium. The center of the cultured dish was then scratched using a P200 pipet tip, washed 2 times with serumfree medium, and the culture was continued for 16 hours in $10 \%$ FBS + medium, with or without ADM or VEGF (Invitrogen). Images of the scratched areas at 0 hours and after 16 hours were captured using a light microscope (Olympus, Tokyo, Japan). The cell-covered area at 16 hours was determined as a percentage of the cell-free area at 0 hours measured in three fields per well using ImageJ software version 1.46e $(\mathrm{NIH}$, Bethesda, MD; http://rsb.info.nih.gov/ij/index.html). The experiment was repeated three times on separate occasions. For the study of EAhy926 cells and human retinal endothelial cells, they were grown in 35-mm dishes, and the coverage of the scratch area was evaluated at 6 hours with or without ADM. 
Retinal Vascular Development in DI-E-RAMP2 ${ }^{-/-}$Mice

All of the images shown were captured using a fluorescence microscope. The isolectin-B4-stained endothelial network was analyzed on flat-mount specimens. In P6, the numbers of filopodial extensions at the retinal angiogenic front were quantified in 16 fields $(200 \mu \mathrm{m} \times 200 \mu \mathrm{m}$ in each field) from four retinas per group. The total number of filopodia was normalized to a standard endothelial vessel length of $1000 \mu \mathrm{m}$, which was measured and defined according to previously reported protocols. ${ }^{25,28}$ The density of front vessel branches was calculated in 16 fields $(200 \mu \mathrm{m} \times 400 \mu \mathrm{m}$ in each field) from four retinas per group. Vascular progression was measured by defining a straight line from the angiogenic front to the center of the retina for each retinal quadrant in low magnification, and 24 quadrants from six retinas per group were used for quantification. In P11, the vascular branch point was counted in 16 fields $(200 \mu \mathrm{m} \times 400 \mu \mathrm{m}$ in each field) from four retinas per group.

For the analysis of endothelial proliferation, Ki-67 (Abcam) immunostaining was performed in P10, and the numbers of Ki-67 and isolectin-B4 double-positive cells were counted in 12 cross sections from three retinas per group.

\section{Intravitreal Antibody Injection}

Anti-ADM antibody kindly provided by Dr. Tanaka was used for intravitreal administration. In the OIR model, mice underwent intravitreal injection on $\mathrm{P} 13 ; 1.5 \mu \mathrm{L}$ of antiADM antibody (ADMab) was intravitreally injected at the temporal cornea-scleral junction using a Hamilton syringe equipped with a 32-G needle under a stereoscopic surgical microscope. As control, the eye received an intravitreal injection of $1.5 \mu \mathrm{L}$ of mouse $\operatorname{IgG}$ (Abcam) at the same position. After the procedure, the mice were administered moxifloxacin hydrochloride antibiotic drops (Vegamox Ophthalmic Solution; Alcon, Fort Worth, TX). Avascular zone and neovascular tufts were analyzed on P17.

\section{Statistical Analysis}

Values are expressed as means \pm SEM. Student's $t$-test and one-way analysis of variance, followed by the Tukey or Dunnett test were used to determine the significance of differences. Values of $P<0.05$ or $P<0.01$ were considered significant.

\section{Results}

Pathological Angiogenesis Is Mitigated in Heterozygous ADM KO $\left(A D M^{+/-}\right)$Mice in OIR

In the OIR model, mice were exposed to $75 \%$ oxygen for 5 days, from P7 to P12, the period (hyperoxic phase) during which oxygen-induced loss of retinal vessels (vaso-obliteration) occurs. After the mice were returned to normoxic conditions (room air) for 5 days, from P12 to P17 (hypoxic phase), the hyperoxia-induced vessel loss led to pathological angiogenesis. We initially compared the retinal angiogenesis at P12 among WT, $A D M^{+/-}$, and $R A M P 2^{+/-}$mice. In retinal flat-mount specimens, we did not detect avascular zones in WT mice kept under normoxia. Mice kept under hyperoxia showed the existence of avascular zones in the central region of the retina; however, we detected no significant differences in the size of the avascular zones among the three mouse types (WT, $34.1 \pm 1.3 \% ; \mathrm{ADM}^{+/-}, 33.3 \pm 1.3 \% ; \mathrm{RAMP}^{+/-}$, $36.4 \pm 1.8 \%$ ), indicating no genotype-dependent differences in the oxygen-induced loss of retinal vessels (Figure 1, A and B). We also found no differences in the hypoxic area at this stage (Supplemental Figure S1). These data indicate that there was no difference in the vascular development and ischemic level among these mice at the start of hypoxiainduced neovascularization.

We next analyzed the time course of ADM expression during retinal development in WT neonates, with and without OIR (Figure 1C). Under normoxic conditions, ADM expression was unchanged or declined slightly from P12 to P17 (0.94 \pm 0.17 -fold at P13 to $0.33 \pm 0.03$-fold at P17). By contrast, neonates subjected to OIR showed prominent up-regulation of ADM from P13 (5.45 \pm 0.83 fold). This suggests ADM expression is induced by hypoxia in OIR. The up-regulated ADM expression persisted until P17 (3.17 \pm 0.25 -fold), though it declined somewhat over that period. However, RAMP2 expression was down-regulated once at $\mathrm{P} 13$, and its expression returned from P15 to P17 (Figure 1D).

We then analyzed retinas at the end of the hypoxic phase (P17) and found that neovascular tuft formation, which is the aneurysmal formation of retinal arteries representing pathological angiogenesis, was significantly reduced in $A D M^{+-1}$ mice $(7.0 \pm 0.4 \%)$, as compared to WT mice $(11.0 \pm 1.3 \%)$ (Figure 2, A and B). In addition, in HE-stained cross sections prepared on P17, retinas from OIR model mice exhibited vascular nuclei extending into the vitreous from the retinal surface (Figure 2C). The numbers of cell nuclei on the vitreal side of the internal limiting membrane were significantly lower in $A D M^{+-}$mice $(20.0 \pm 3.3)$ than WT mice $(36.8 \pm 4.4)$ (Figure 2D), which is also indicative of a smaller degree of pathological angiogenesis in $A D M^{+-}$mice. We detected no significant difference in $R A M P 2^{+/-}$mice (neovascular tufts, $13.1 \pm 1.4 \%$; numbers of nuclei above internal limiting membrane, $33.1 \pm 2.0$ ).

\section{$\mathrm{ADM}^{+/-}$and $\mathrm{RAMP2}^{+/-}$Retinas Show Reduced Avascular Zones and Hypoxic Areas in OIR}

Using both lectin and $\mathrm{H}-1$ staining, we evaluated the retinal vessels and hypoxic areas in P17 retinas. In $A D M^{+/-}$and $R A M P 2^{+/-}$retinas, the hypoxic area was limited to the central region of the retina, with little or no hypoxia detected in the periphery (Figure $3 \mathrm{~A}$ ). We found that both the avascular zone and hypoxic area were significantly smaller in $A D M^{+/-}$ 


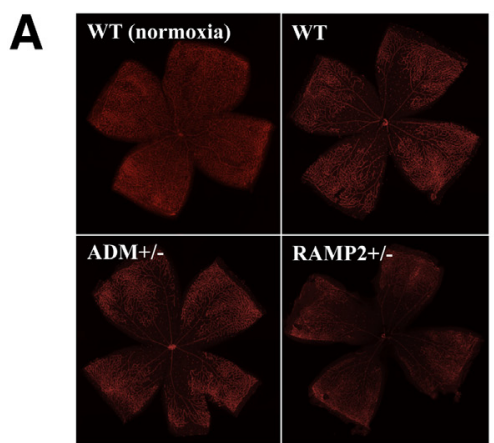

B

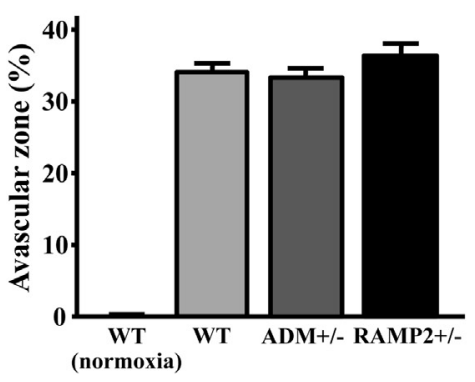

Figure 1 Comparison of retinal angiogenesis among WT, $A D M^{+/-}$, and $R A M P 2^{+/-}$mice soon after high-oxygen treatment (P12) and WT mice kept under normoxia (P12). A: Representative P12 retinal flat-mount specimens with lectin-staining. B: Bar graph comparing the avascular zone percentage per whole retina among WT, $A D M^{+/-}$, and $R A M P 2^{+/-}$mice. Bars depict means $\pm \operatorname{SEM}(n=6$ in each group). $\mathbf{C}$ and $\mathbf{D}$ : Quantitative real-time PCR analysis of $A D M$ and RAMP2 gene expression in WT mice from P12 to P17. Retinas were collected from neonates at the indicated stage and used for mRNA extraction. The bar graph depicts the relative levels of ADM and RAMP2 gene expression; the level obtained in the normoxia group at P12 was assigned a value of 1 . White bars: neonates kept under normoxic conditions (room air). Black bars: neonate exposed to hyperoxia $\left(75 \% \mathrm{O}_{2}\right)$ from P7 to P12 (OIR group). The 0IR group showed prominent up-regulation of ADM at P13 and remained elevated from P13 to P17 (C). However, RAMP2 expression was down-regulated at P13, and its expression returned from P15 to P17 (D). Bars depict means \pm SEM. ${ }^{* *} P<0.01$ ( $n=5$ to 8 in each group).

C

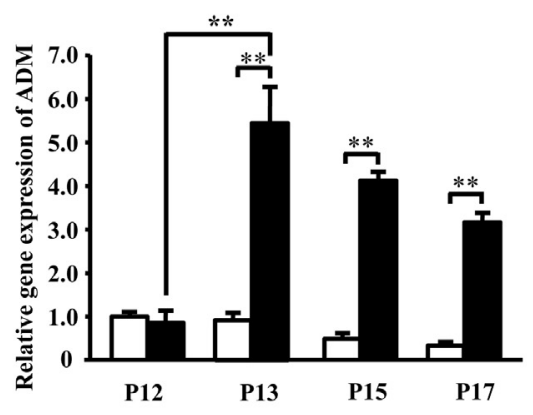

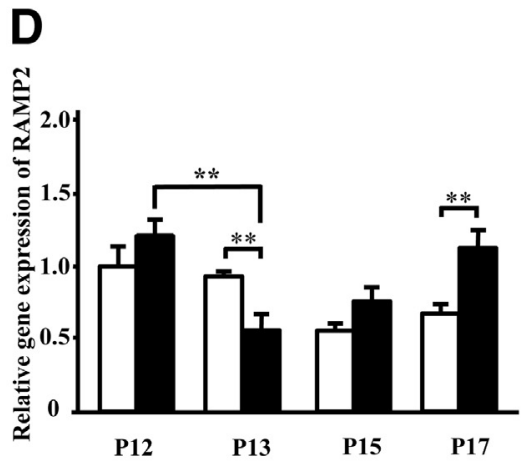

(14.2 $\pm 2.3 \%$ and $3.1 \pm 0.6 \%$, respectively) than WT mice $(25.6 \pm 3.2 \%$ and $9.9 \pm 1.9 \%$, respectively) (Figure 3, B and C). Similarly, in $R A M P 2^{+/-}$mice, the avascular zone tended to be smaller $(19.8 \pm 1.3 \%)$ (Figure 3B) and the hypoxic area was significantly smaller $(5.2 \pm 0.9 \%)$ than in WT mice (Figure 3C). The reductions in the avascular zone and hypoxic area suggest physiological angiogenesis is enhanced in both KO strains. In the WT retina, $\mathrm{H}-1-$ positive (hypoxic) areas were detected even within lectin-positive areas in the retinal periphery. However, as stated above, in $A D M^{+/-}$and $R A M P 2^{+/-}$retinas, the hypoxic area was limited to the central region of the retina, with little or no hypoxia detected in the periphery (Figure 3A). This may indicate that in the WT retina, vascular formation in peripheral regions could not fully compensate for the ischemia caused by OIR, whereas it was almost entirely compensated for in $A D M^{+/-}$and $R A M P 2^{+/-}$ retinas.

\section{Altered Expression of Angiogenic Factors in $A D M^{+/-}$ Retinas after OIR Treatment}

We also investigated retinal gene expression in the OIR model (Figure 4A). In WT mice, ADM and RAMP2 were up-regulated after OIR (P17). The expressions of VEGF, vascular endothelial growth factor receptor 1 (VEGFR1), and eNOS were all significantly up-regulated in WT OIR model; however, the up-regulation was suppressed in $A D M^{+/-}$mice. In Western blot analysis (Figure 4, B and C), we also confirmed the reduction of VEGF protein level in $A D M^{+/-}$. Activation of eNOS (represented by the p-eNOS/eNOS ratio) was also suppressed in $A D M^{+/-}$. Apparently, the lower ADM in $A D M^{+/-}$affected several angiogenic pathways under ischemic conditions. Compared with $A D M^{+/-}$, changes in VEGF and eNOS expression were smaller in $R A M P 2^{+/-}$(Supplemental Figure S2).

\section{ADM Enhances Proliferation and Migration of Endothelial Cells in Vitro}

We directly assessed the effects of ADM on endothelial cells in vitro. At first, we used RF/6A135 CRECs and performed scratch-wound assays. We evaluated the recovery of the reendothelialized monolayer within the scratched area. ADM dose-dependently increased the degree of recovery, which is indicative of the ADM-induced enhancement of CREC proliferation and migration (Figure 5, A and B).

Next, we analyzed the effect of RAMP2 overexpression in endothelial cells. Under ADM stimulation, EAhy926 endothelial cells, which overexpress RAMP2 (RAMP2O/ E), showed significantly enhanced coverage in the scratchwound assay (Figure 5, C and D). Furthermore, using human retinal endothelial cells, we confirmed that ADM enhances cellular proliferation and migration (Figure 5, $\mathrm{E}$ and $\mathrm{F}$ ).

\section{Effects of RAMP2 Deletion on Retinal Vascular Development in DI-E-RAMP2 ${ }^{-/-}$Mice}

Our finding that OIR-induced changes in retinal angiogenesis were smaller in $R A M P 2^{+/-}$might be due to our need to use heterozygous KO mice. Therefore, to further analyze the involvement of RAMP2 in retinal angiogenesis, we developed an inducible endothelial cell-specific RAMP2 KO (DIE-RAMP2 ${ }^{-1-}$ ) mouse line. With this model, we were able to induce RAMP2 deletion at desired stages of neonatal growth through tamoxifen-induced Cre recombinase activation. 

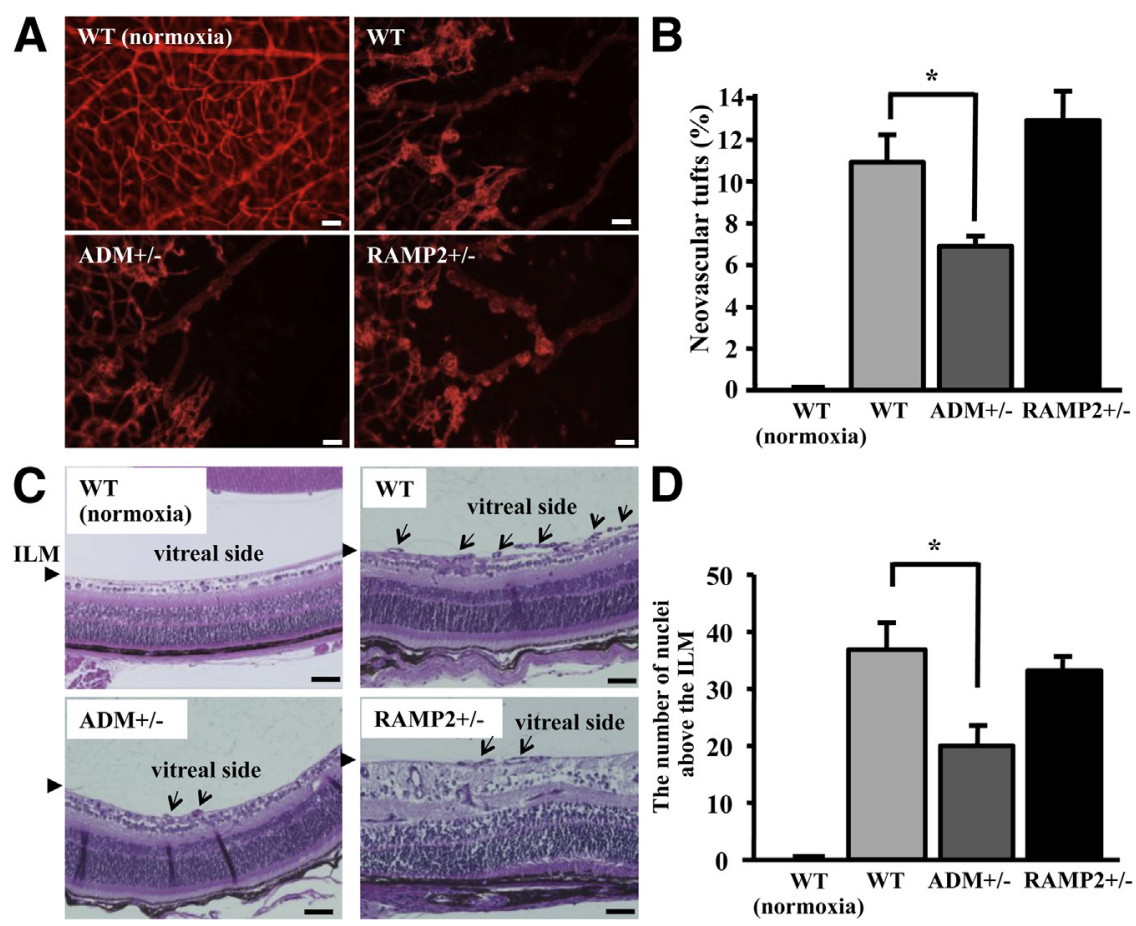

Figure 2 Effect of genotype on the development of neovascular tufts (retinal pathological angiogenesis) at the border of avascular zones on P17 in 0IR model mice. A: Representative retinal flat-mount specimens with lectin-staining. Scale bar $=50 \mu \mathrm{m}$. B: Bar graph comparing the percentages of neovascular tuft area per whole retina. $A D M^{+/-}$mice showed a significant reduction of neovascular tufts. WT mice kept under normoxia did not show neovascular tuft formation. Bars depict means \pm SEM. ${ }^{*} P<0.05(n=6$ in each group). C: Retinal sections with H\&E staining. Arrowheads indicate the internal limiting membrane (ILM). Arrows indicate pathological intravitreal angiogenesis. Scale bar $=50 \mu \mathrm{m}$. D: Bar graph comparing the numbers of cell nuclei extending from the ILM into the vitreous. $\mathrm{ADM}^{+/-}$ mice showed a significant reduction of the numbers of cell nuclei. Bars depict means \pm SEM. ${ }^{\star} P<0.05$ ( $n=6$ in each group).

Using this model, we analyzed earlier stages of retinal vascular development (on P6, P10, and P11).

We first analyzed retinal vascular development on P6 after administration of tamoxifen daily from P1 to P3 (Figure 6A). At this stage, retinal vessels were elongating from the center of the retina toward the periphery. Examination of lectin-stained whole retinas (Figure 6B) revealed that the vascular progression was significantly retarded in DI-E-RAMP2 ${ }^{-1-}$ mice, as compared to control mice $(75.3 \pm 2.0 \%$ versusersus $83.1 \pm 2.4 \%$ ) (Figure 6C). Under higher magnification (Figure 6B), we found that the number of filopodia did not differ between DI-E-RAMP2 ${ }^{-/-}$and control retinas ( $85.1 \pm 9.1$ and $81.5 \pm 6.2$, respectively), but the vascular density was significantly greater at the front of the vascular progression in DI-E-RAMP2 ${ }^{-1-}$ retinas $(49.0 \pm 1.2 \%$ versusersus $40.3 \pm 1.3 \%)$ (Figure 6C).

We then analyzed the retinal vascular development on P10 and P11 after administration of tamoxifen daily from P5 to P8 (Figure 7A). At this stage, vascular progression has reached the peripheral regions of the retina. In DI-E$\mathrm{RAMP}^{-/-}$retinas, the number of vessel branch points was significantly lower than control $(47.8 \pm 9.9$ versus $80.3 \pm$
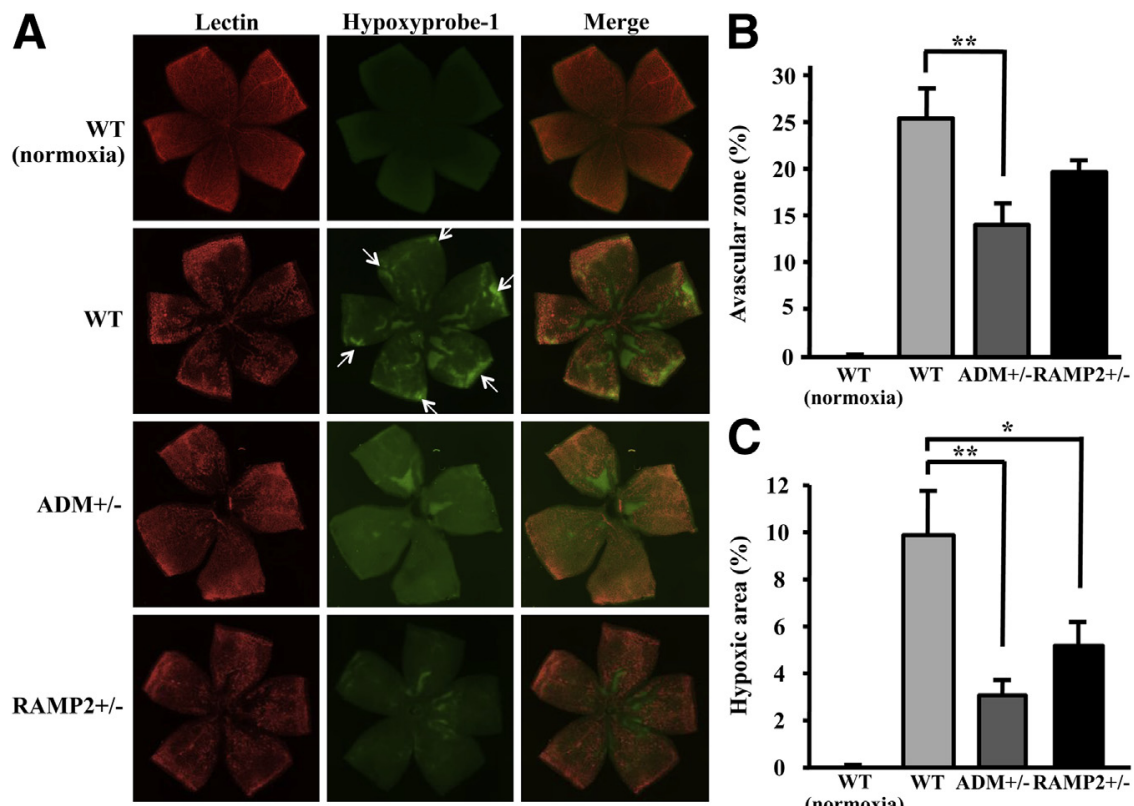

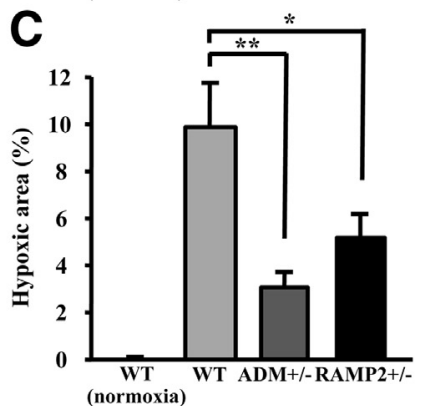

Figure 3 Effect of genotype on the relative size of avascular zones and hypoxic areas on P17 in OIR model mice. A: Lectin and hypoxyprobe-1 staining showing the avascular zone and hypoxic area in retinal flat-mounts. In WT retinas, a hypoxic area was detected at the periphery (arrows) and in the central region, whereas little or no peripheral hypoxia was detected in $\mathrm{ADM}^{+/-}$ and $R A M P 2^{+/-}$. B and C: Bar graphs comparing the avascular zone (B) and hypoxic area (C) percentages per whole retina between WT and $A D M^{+/-}$or $\mathrm{RAMP2}^{+/-}$retinas. $\mathrm{ADM}^{+/-}$retinas showed significant reductions in avascular zone and hypoxic area, and $\mathrm{RAMP}^{+/-}$showed significant reduction in hypoxic area. WT mice kept under normoxia showed no hypoxic area. Bars depict means \pm SEM. ${ }^{*} P<0.05,{ }^{*} P<0.01(n=6$ in each group). 

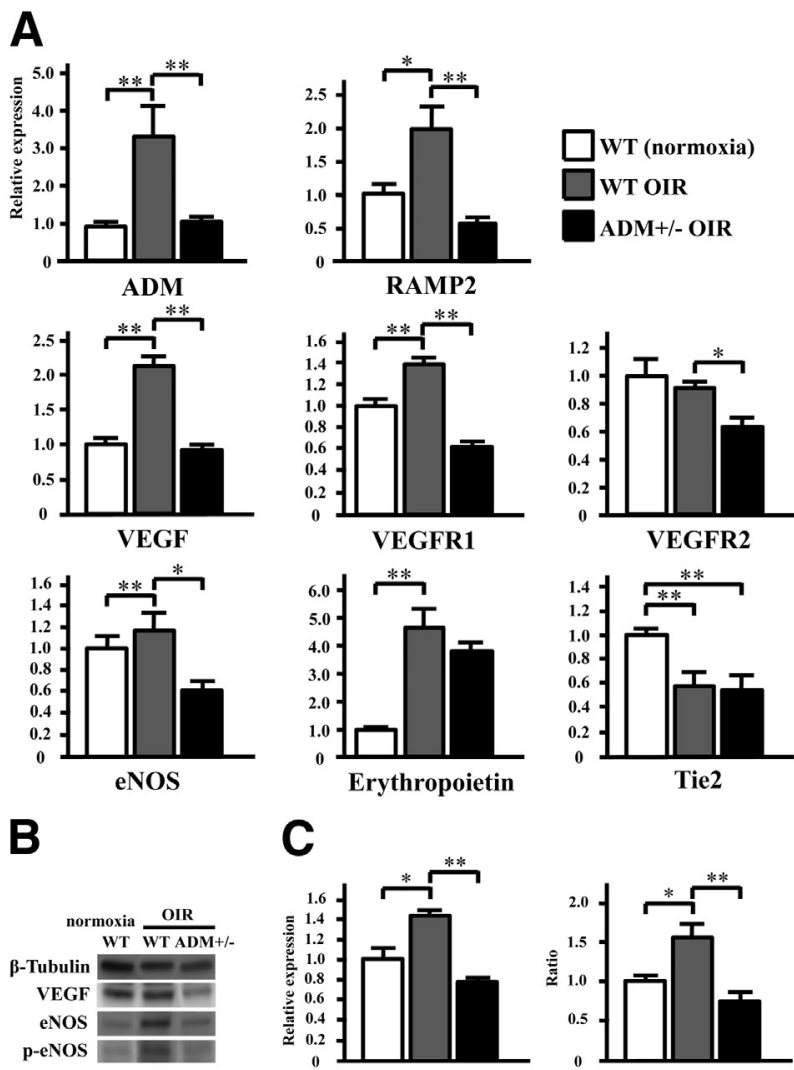

C
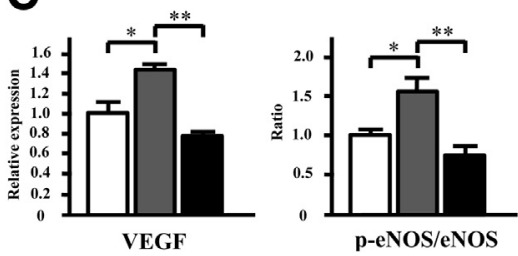

Figure 4 Comparison of mRNA and protein expression between WT and $A D M^{+/-}$. A: Bar graphs show the relative expression of the indicated genes in WT and $A D M^{+/-}$retinas on P17 of OIR and WT mice kept under normoxia. When subjected to OIR, $A D M^{+/-}$retinas showed less expression of angiogenic factors, including VEGF and eNOS. B: Western blot analysis of VEGF, eNOS, and phosphorylated eNOS (p-eNOS) in WT and $A D M^{+/-}$retinas on P17 and WT mice kept under normoxia. C: Optical densities were quantified, and the result of the relative expression of VEGF and ratio of p-eNOS/NOS (eNOS activation level) is shown in the bar graph. In protein analysis, $A D M^{+/-}$ retinas also showed less expression of VEGF and less activation of eNOS. The level obtained in the WT normoxia group was assigned a value of 1 . Bars are means \pm SEM. ${ }^{*} P<0.05,{ }^{*} P<0.01(n=5$ to 7 in $\mathbf{A}$ and $n=4$ in $\mathbf{C})$.

1.8) (Figure 7, B and C). At P10, both DI-E-RAMP2 ${ }^{-1-}$ and control retinas did not show TUNEL/isolectin B4 doublepositive cells (data not shown). However, DI-E-RAMP2 ${ }^{-1-}$ retinas showed significantly lower Ki-67/isolectin B4 doublepositive cells (proliferating endothelial cells) compared with control ( $20.5 \pm 1.8$ versus $15.3 \pm 0.6)$ (Figure $7, \mathrm{D}$ and E).

Taken together, these observations suggest maturation of the vessels is delayed in DI-E-RAMP2 ${ }^{-1-}$ mice. RAMP2mediated effects may be important for physiological retinal angiogenesis at an earlier stage than in the OIR model.

\section{Intravitreal Injection of Anti-ADM Antibody Reduces Only Pathological Retinal Angiogenesis}

Finally, we evaluated the effects of ADM blockade through intravitreal administration of an ADMAb. In the OIR model, WT mice underwent intravitreal injection of mouse $\operatorname{IgG}$ or ADMAb on P13. After lectin staining of the whole retina
(Figure 8A) and at the border of the avascular zone (Figure 8A), we evaluated the relative size of the avascular zone and the degree of neovascular tuft development in each group (Figure 8B). We found that ADMAb treatment shrank the neovascular tufts; however, it did not change the avascular zone. Thus, ADMAb suppressed only the pathological angiogenesis and did not suppress physiological angiogenesis.

\section{Discussion}

VEGF has been shown to play a central role in pathological retinal angiogenesis, and anti-angiogenic therapy with antiVEGF antibody is now used for clinical treatment of related ailments such as age-related macular degeneration, DR retinal vein occlusion, and retinopathy of prematurity. ${ }^{1-4}$ However, the efficacy of anti-VEGF antibody is still not adequate to prevent eventual blindness in advanced cases, so other therapeutic targets through which to control the progression of pathological angiogenesis are being sought. ADM is an angiogenic factor induced by ischemia, and the fact that intravitreous ADM levels are elevated in patients with proliferative retinal disease implicates ADM in the development and progression of pathological angiogenesis. ${ }^{21-23} \mathrm{In}$ analogous fashion, ADM expression is up-regulated in several tumor models, and its inhibition reduces tumor growth in vivo. ${ }^{12,29-31}$ However, ADM also acts as an antioxidant, anti-inflammatory, and antiapoptotic mediator, and its specific role in retinal angiogenesis related to ischemic retinopathy remains unclear. To our knowledge, this is the first experimental study addressing the involvement of endogenous ADM in retinal angiogenesis in vivo.

We first found that retinal ADM expression is upregulated in our OIR model, and we suggest that ADM, like VEGF, is a key angiogenic mediator induced by ischemia. On P12, we detected no difference in vascular density among WT, $A D M^{+/-}$, and $R A M P 2^{+/-}$retinas, indicating that ADM deficiency does not directly affect oxygeninduced loss of retinal vessels (vaso-obliteration). We also found $A D M^{+/-}$and $R A M P 2^{+/-}$neonates did not show any abnormalities in retinal vessel development under normoxia (data not shown). On P17 (the end of hypoxic phase), however, neovascular tufts, the avascular zone, and the hypoxic area were all smaller in $A D M^{+/-}$than WT mice. These findings suggest that ADM deficiency suppressed pathological angiogenesis that resulted in less neovascular tufts formation, whereas it spared physiological angiogenesis that resulted in a smaller avascular zone and hypoxic area.

ADM reportedly up-regulates expression of both VEGF and eNOS. ${ }^{12,32,33}$ Consistent with that idea, we found that levels of VEGF and eNOS expression were reduced in $A D M^{+/-}$mice on P17, suggesting ischemia-induced excessive expression of VEGF and eNOS is moderated in $A D M^{+/}$ mice. Implications of multiple angiogenic pathways may be related to the altered angiogenesis in $A D M^{+/-}$retinas. We speculate that ADM activates several angiogenic pathways 
A

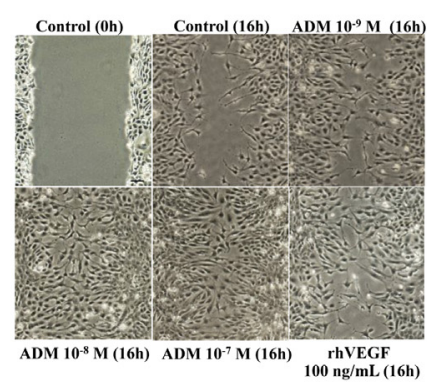

C

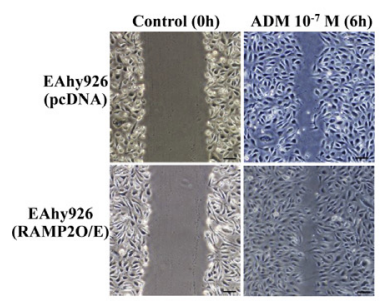

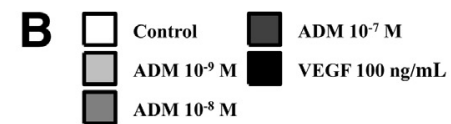

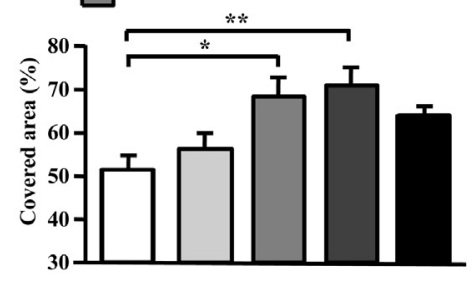

E

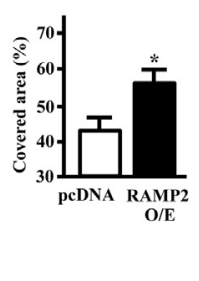

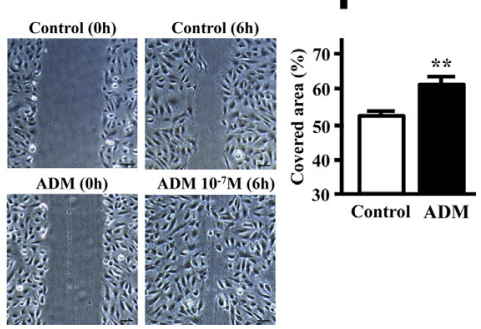

Figure 5 In vitro scratch-wound assay. A: Representative photomicrographs of a control (at 0 hours) and re-endothelialized monolayer (at 16 hours) of RF/ 6A135 chorioretinal endothelial cells (CRECS) after a scratch with or without ADM. Assays performed in the presence of recombinant human VEGF (rhVEGF) served as a positive control. B: Bar graph showing the percentage cell-covered area (per cell free area at 0 hours) in scratch-wound assay using RF/6A135. ADM dose-dependently increased coverage. C: Control (at 0 hours) and re-endothelialized monolayer (at 6 hours) of EAhy926 endothelial cells, which overexpress RAMP2 gene (RAMP20/E), or control cells transfected with empty pcDNA3.1 $1^{+}$vector (pcDNA). D: Bar graph showing the percentage cell-covered area (per cell free area at 0 hours) in scratch-wound assay in RAMP20/E and control cells. RAMP2 overexpression enhanced the cellular proliferation and migration. E: Control (at 0 hours) and re-endothelialized monolayer (at 6 hours) of human retinal endothelial cells. F: Bar graph showing the percentage cell-covered area (per cell free area at 0 hours) in scratch-wound assay using human retinal endothelial cells. ADM stimulation also enhanced proliferation and migration of human retinal endothelial cells. Bars depict means \pm SEM. ${ }^{*} P<$ $0.05,{ }^{*} P<0.01$ ( $n=9$ in $\mathbf{B}$ and $n=6$ in $\mathbf{D}$ and $\left.\mathbf{F}\right)$. under ischemic conditions. As a result, neovascular tuft formation was significantly suppressed in $A D M^{+/-}$. Reduction of pathological angiogenesis (including neovascular tuft formation) may help to promote physiological angiogenesis, and therefore reduced ischemia in $A D M^{+/-}$.

As in $A D M^{+/-}$retinas, the avascular zone and hypoxic area were reduced in $R A M P 2^{+/-}$retinas, indicating the ADMRAMP2 system is crucially involved in retinal angiogenesis. However, the changes seen in $R A M P 2^{+/-}$mice were not as pronounced as in $A D M^{+/-}$mice. This may be explained in part by offsetting effects of other RAMP isoforms, especially RAMP3. In $R A M P 2^{+/-}$mice, expression of RAMP3 and
CLR remains normal, and the CLR/RAMP3 complex also functions as an ADM receptor. ${ }^{13,14}$

In the present study, we also used retinal endothelial cells to directly assess the effect of ADM in vitro. We found that exogenous ADM administration dose-dependently enhanced the proliferation and migration of retinal endothelial cells in scratch-wound assay. RAMP2 overexpression also enhanced the proliferation and migration of endothelial cells under ADM stimulation. In our assay, both proliferation and migration of the endothelial cells could contribute to the coverage of scratched area. Enhancement of both proliferation and migration of endothelial cells by ADM was reported
A

Intragastric injection

Control: Corn oil $50 \mu \mathrm{L}$

DI-E-RAMP2-/-: Tamoxifen $50 \mu \mathrm{g}(1 \mathrm{mg} / \mathrm{mL})$

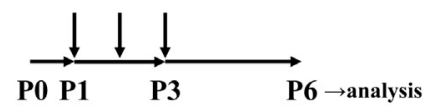

C
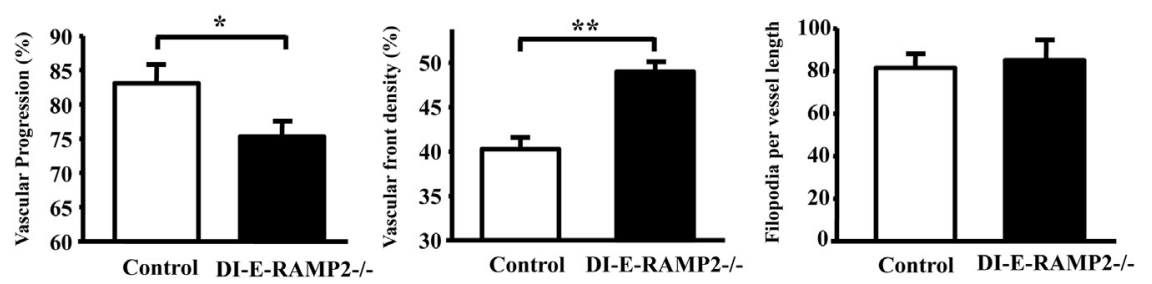

Figure 6 Effects of induced RAMP2 deletion on retinal vascular development in DI-E-RAMP2 ${ }^{-1-}$ mice on P6. A: Protocol for RAMP2 deletion on P6. Cre recombinase was activated by intragastric injection of tamoxifen on the indicated days; controls were treated with corn oil. B: Representative photomicrographs showing retinal vessel development on P6 in DI-E-RAMP2 ${ }^{-1-}$ and control retinas. Shown are lectinstained whole retinas (upper panels) and the developing vascular front at the periphery (lower panels). Scale bar $=50 \mu \mathrm{m}$ (lower panels). C: Bar graphs showing the percentage vascular progression $(n=6)$, percentage vascular front density $(n=4)$, and numbers of filopodia per vessel length $(n=4)$. Data in $\mathbf{C}$ are means \pm SEM. ${ }^{*} P<0.05,{ }^{*} P<0.01$. 


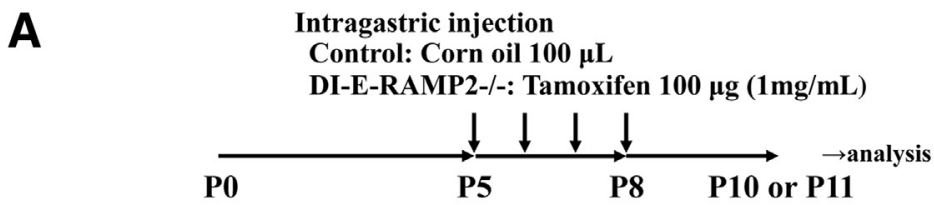

B
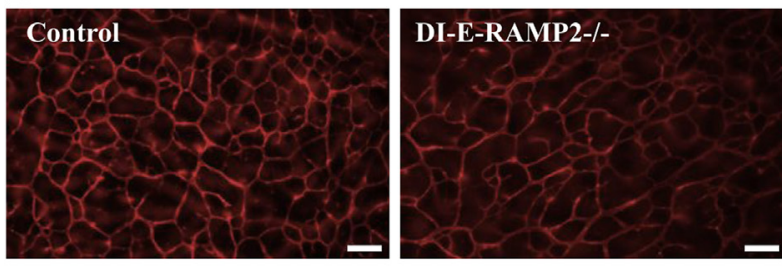

D
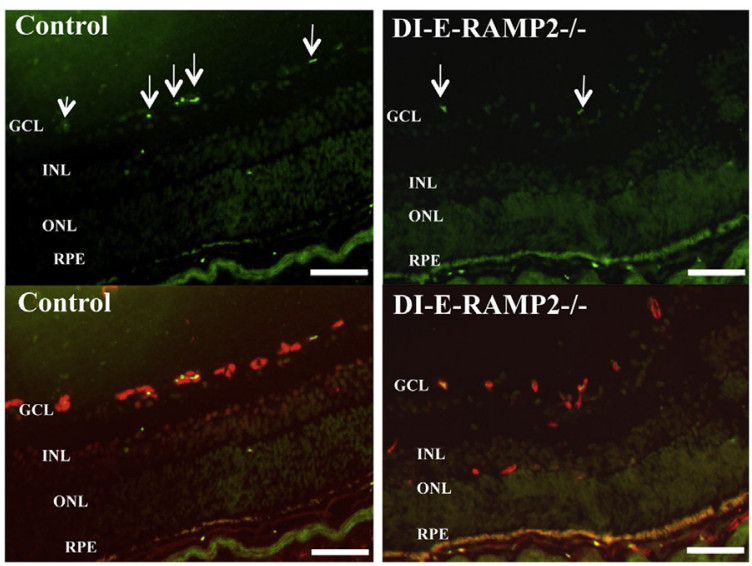

previously, ${ }^{12,34}$ and our data reconfirmed the effects in retinal endothelial cells. These data further support the notion that the ADM-RAMP2 system is strongly involved in retinal angiogenesis by enhancing both retinal endothelial cell proliferation and migration.

Because homozygous ADM or RAMP2 $\mathrm{KO}$ is embryonically lethal by mid-gestation, analysis of the ADMRAMP2 system during retinal development has been limited. We used a line of drug-inducible endothelial cellspecific RAMP2 KO mice (DI-E-RAMP2 ${ }^{-/-}$). With this model, we were able to delete the $R A M P 2$ gene from endothelial cells through administration of tamoxifen. During neonatal development, retinal vessels grow from the central region to the periphery during the period extending from $\mathrm{P} 0$ to $\mathrm{P} 9$. As compared to control, DI-E-RAMP2 ${ }^{-l-}$ retinas showed abnormal vessel development on $\mathrm{P} 6$, with delayed vessel progression in the periphery and excessive branching at the vascular front. From the observation of DIE-RAMP2 ${ }^{-/-}$, the ADM-RAMP2 system may be important for physiological retinal vascular development at a relatively earlier stage (before P11) than the OIR model (P12-17).

Interestingly, the abnormality in the early stage of retinal vascular development of DI-E-RAMP $2^{-1-}$ resembles the reported phenotype in Delta-like ligand 4 (Dll4) KO mice. ${ }^{35,36}$ In addition, Yurugi-Kobayashi et $\mathrm{al}^{37}$ reported ADM induces Notch activation during endothelial cell development. ADM receptors couple to Gs $\alpha$, activating adenylate cyclase and the
Figure 7 Effects of induced RAMP2 deletion on retinal vascular development in DI-E-RAMP2 ${ }^{-/-}$ mice on P11. A: Protocol for RAMP2 deletion on P11. Cre recombinase was activated by intragastric injection of tamoxifen on the indicated days; controls were treated with corn oil. B: Representative lectin staining showing retinal vessels in a central region of a DI-E-RAMP2 ${ }^{-/}$and control retina on P11. Scale bar $=50 \mu \mathrm{m}$. C: Comparison of the number of vessel branch points per field between control and DI-E-RAMP2 ${ }^{-/-}$retinas. Vessel branch points are decreased in DI-E-RAMP2 ${ }^{-/-}$. D: Cross sections of retinas from control and DI-E-RAMP2 ${ }^{-1-}$ mice on $\mathrm{P} 10$. Upper panels show immunostaining of Ki-67 (green fluorescent cells indicated by arrows are Ki-67-positive cells). Lower panels show double staining of Ki-67 (green) and isolectin B4 (red). GCL, ganglion cell layer; INL, inner nuclear layer; ONL, outer nuclear layer; RPE, retinal pigment epithelial cell layer. Scale bar $=50 \mu \mathrm{m}$. E: Comparison of the numbers of $\mathrm{Ki}-67$ and isolectin $\mathrm{B} 4$ double-positive cells per section between control and DI-E-RAMP2 ${ }^{-1-}$ retinas. Ki-67-positive proliferating endothelial cells are decreased in DI-ERAMP2 $^{-1-}$. Data in $\mathbf{C}$ and $\mathbf{E}$ are means \pm SEM. ${ }^{*} P<$ 0.05 ( $n=4$ in $\mathbf{C}$ and $n=3$ in $\mathbf{E})$.
cAMP-PKA pathway, leading to PKA-mediated activation of Notch signaling. ${ }^{37}$ This suggests the abnormal vascular development seen in DI-E-RAMP2 ${ }^{-/-}$may be related to abnormal Notch signaling.
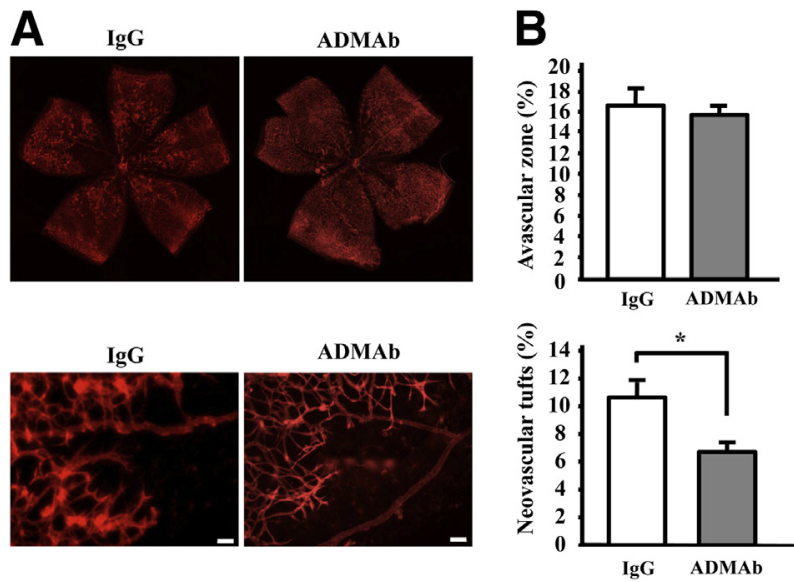

Figure 8 Effect of intravitreal injection of anti-ADM antibody on OIRrelated angiogenesis. After OIR, WT mice underwent intravitreal injection of mouse IgG or anti-ADM antibody (ADMAb) on P13. Avascular zone and neovascular tufts were analyzed on P17. A: Shown are representative lectinstained whole retinas (upper panels) and neovascular tufts (pathological retinal angiogenesis) at the border of an avascular zone (lower panels). Scale bar $=50 \mu \mathrm{m}$ (lower panels). B: Bar graphs comparing the avascular zone and neovascular tufts. ADMAb reduced only neovascular tufts. Bars are means \pm SEM. ${ }^{*} P<0.05$ ( $n=6$ in each group). 
Given that ADM deficiency reduced pathological angiogenesis in OIR model, we tested the effect of intravitreal injection of ADMAb. The ADMAb reduced only pathological retinal angiogenesis. From a therapeutic viewpoint, our data suggest the ADM-RAMP2 system could be a novel and improved therapeutic target for controlling only pathological retinal angiogenesis, with little or no effect on physiological angiogenesis in OIR.

In this study, we demonstrated reduced retinal angiogenesis in $A D M^{+/-}$mice and the usefulness of ADMAb treatment in OIR. Recently, Yuda et a ${ }^{38}$ reported that ADM is also involved in choroidal neovascularization $(\mathrm{CNV})$ and $A D M^{+/-}$ showed enhanced pathological angiogenesis and vascular leakage in a laser-induced CNV model. From the viewpoint of angiogenesis, our results seem to contradict theirs. However, the pathogenesis of CNV consists of inflammation as well as angiogenesis. Several studies have suggested the critical anti-inflammatory roles of $\mathrm{ADM}^{39}$ In the $\mathrm{CNV}$ model, inflammation is the primary factor, which induces neovascularization. However, hypoxia is the primary factor in the OIR model. We estimate that the enhanced inflammatory reaction of $A D M^{+/-}$in laser-induced $\mathrm{CNV}$ exacerbated the pathological angiogenesis. Therefore, we should pay attention to the pathogenesis of each situation to determine whether we should suppress or enhance the ADM-RAMP2 system in future therapeutic approaches. Furthermore, future studies should determine whether ADMAb treatment is generally effective for pathological retinal angiogenesis in retinopathies such as DR and retinal vein occlusion.

\section{Acknowledgments}

ADM was kindly provided by Dr. Kenji Kangawa (National Cardiovascular Center Research Institute, Japan), anti-ADM antibody was kindly provided by Dr. Hitoshi Tanaka (Shionogi \& Co., Ltd., Osaka, Japan), human retinal ECs were kindly divided by Dr. Kousuke Noda (Hokkaido University, Japan), and EAhy926 ECs were kindly provided by Dr. Cora-Jean S. Edgell (University of North Carolina).

\section{Supplemental Data}

Supplemental material for this article can be found at http://dx.doi.org/10.1016/j.ajpath.2013.02.015.

\section{References}

1. Wong TY, Liew G, Mitchell P: Clinical update: new treatments for age-related macular degeneration. Lancet 2007, 370:204-206

2. Nicholson BP, Schachat AP: A review of clinical trials of anti-VEGF agents for diabetic retinopathy. Graefes Arch Clin Exp Ophthalmol 2010, 248:915-930

3. Wong TY, Scott IU: Clinical practice. Retinal-vein occlusion. N Engl J Med 2010, 363:2135-2144

4. Mintz-Hittner HA, Kennedy KA, Chuang AZ: Efficacy of intravitreal bevacizumab for stage $3+$ retinopathy of prematurity. N Engl J Med 2011, 364:603-615
5. Schaal S, Kaplan HJ, Tezel TH: Is there tachyphylaxis to intravitreal anti-vascular endothelial growth factor pharmacotherapy in age-related macular degeneration? Ophthalmology 2008, 115:2199-2205

6. Keane PA, Liakopoulos S, Ongchin SC, Heussen FM, Msutta S, Chang KT, Walsh AC, Sadda SR: Quantitative subanalysis of optical coherence tomography after treatment with ranibizumab for neovascular age-related macular degeneration. Invest Ophthalmol Vis Sci 2008, 49:3115-3120

7. Kitamura K, Kangawa K, Kawamoto M, Ichiki Y, Nakamura S, Matsuo H, Eto T: Adrenomedullin: a novel hypotensive peptide isolated from human pheochromocytoma. Biochem Biophys Res Commun 1993, 192:553-560

8. Fujita Y, Mimata H, Nasu N, Nomura T, Nomura Y, Nakagawa M: Involvement of adrenomedullin induced by hypoxia in angiogenesis in human renal cell carcinoma. Int J Urol 2002, 9:285-295

9. Wang X, Yue TL, Barone FC, White RF, Clark RK, Willette RN, Sulpizio AC, Aiyar NV, Ruffolo RR Jr, Feuerstein GZ: Discovery of adrenomedullin in rat ischemic cortex and evidence for its role in exacerbating focal brain ischemic damage. Proc Natl Acad Sci U S A 1995, 92:11480-11484

10. Nguyen SV, Claycomb WC: Hypoxia regulates the expression of the adrenomedullin and HIF-1 genes in cultured HL-1 cardiomyocytes. Biochem Biophys Res Commun 1999, 265:382-386

11. Shindo T, Kurihara $Y$, Nishimatsu H, Moriyama N, Kakoki M, Wang Y, Imai Y, Ebihara A, Kuwaki T, Ju KH, Minamino N, Kangawa K, Ishikawa T, Fukuda M, Akimoto Y, Kawakami H, Imai T, Morita H, Yazaki Y, Nagai R, Hirata Y, Kurihara H: Vascular abnormalities and elevated blood pressure in mice lacking adrenomedullin gene. Circulation 2001, 104:1964-1971

12. Iimuro S, Shindo T, Moriyama N, Amaki T, Niu P, Takeda N, Iwata H, Zhang Y, Ebihara A, Nagai R: Angiogenic effects of adrenomedullin in ischemia and tumor growth. Circ Res 2004, 95:415-423

13. McLatchie LM, Fraser NJ, Main MJ, Wise A, Brown J, Thompson N, Solari R, Lee MG, Foord SM: RAMPs regulate the transport and ligand specificity of the calcitonin-receptor-like receptor. Nature 1998, 393:333-339

14. Parameswaran N, Spielman WS: RAMPs: the past, present and future. Trends Biochem Sci 2006, 31:631-638

15. Ichikawa-Shindo Y, Sakurai T, Kamiyoshi A, Kawate H, Iinuma N, Yoshizawa $T$, Koyama $T$, Fukuchi J, Iimuro S, Moriyama N, Kawakami H, Murata T, Kangawa K, Nagai R, Shindo T: The GPCR modulator protein RAMP2 is essential for angiogenesis and vascular integrity. J Clin Invest 2008, 118:29-39

16. Okamura T, Ayajiki K, Kangawa K, Toda N: Mechanism of adrenomedullin-induced relaxation in isolated canine retinal arteries. Invest Ophthalmol Vis Sci 1997, 38:56-61

17. Dorner GT, Garhofer G, Huemer KH, Golestani E, Zawinka C, Schmetterer L, Wolzt M: Effects of adrenomedullin on ocular hemodynamic parameters in the choroid and the ophthalmic artery. Invest Ophthalmol Vis Sci 2003, 44:3947-3951

18. Clementi G, Floriddia ML, Prato A, Marino A, Drago F: Adrenomedullin and ocular inflammation in the rabbit. Eur J Pharmacol 2000, 400:321-326

19. Taniguchi T, Kawase K, Gu ZB, Kimura M, Okano Y, Kawakami H, Tsuji A, Kitazawa Y: Ocular effects of adrenomedullin. Exp Eye Res 1999, 69:467-474

20. Yousufzai SY, Ali N, Abdel-Latif AA: Effects of adrenomedullin on cyclic AMP formation and on relaxation in iris sphincter smooth muscle. Invest Ophthalmol Vis Sci 1999, 40:3245-3253

21. Er H, Doganay S, Ozerol E, Yurekli M: Adrenomedullin and leptin levels in diabetic retinopathy and retinal diseases. Ophthalmologica 2005, 219:107-111

22. Ito S, Fujisawa K, Sakamoto T, Ishibashi T: Elevated adrenomedullin in the vitreous of patients with diabetic retinopathy. Ophthalmologica 2003, 217:53-57

23. Lu Y, Xu Y, Tang C: Changes in adrenomedullin in patients with proliferative diabetic retinopathy. Curr Eye Res 2011, 36:1047-1052 
24. Kogata N, Arai Y, Pearson JT, Hashimoto K, Hidaka K, Koyama T, Somekawa S, Nakaoka Y, Ogawa M, Adams RH, Okada M, Mochizuki N: Cardiac ischemia activates vascular endothelial cadherin promoter in both preexisting vascular cells and bone marrow cells involved in neovascularization. Circ Res 2006, 98:897-904

25. Pitulescu ME, Schmidt I, Benedito R, Adams RH: Inducible gene targeting in the neonatal vasculature and analysis of retinal angiogenesis in mice. Nat Protoc 2010, 5:1518-1534

26. Connor KM, Krah NM, Dennison RJ, Aderman CM, Chen J, Guerin KI, Sapieha P, Stahl A, Willett KL, Smith LE: Quantification of oxygeninduced retinopathy in the mouse: a model of vessel loss, vessel regrowth and pathological angiogenesis. Nat Protoc 2009, 4:1565-1573

27. Liang CC, Park AY, Guan JL: In vitro scratch assay: a convenient and inexpensive method for analysis of cell migration in vitro. Nat Protoc 2007, 2:329-333

28. Benedito R, Rocha SF, Woeste M, Zamykal M, Radtke F, Casanovas O, Duarte A, Pytowski B, Adams RH: Notch-dependent VEGFR3 upregulation allows angiogenesis without VEGF-VEGFR2 signalling. Nature 2012, 484:110-114

29. Ouafik L, Sauze S, Boudouresque F, Chinot O, Delfino C, Fina F, Vuaroqueaux V, Dussert C, Palmari J, Dufour H, Grisoli F, Casellas P, Brunner N, Martin PM: Neutralization of adrenomedullin inhibits the growth of human glioblastoma cell lines in vitro and suppresses tumor xenograft growth in vivo. Am J Pathol 2002, 160:1279-1292

30. Kaafarani I, Fernandez-Sauze S, Berenguer C, Chinot O, Delfino C, Dussert C, Metellus P, Boudouresque F, Mabrouk K, Grisoli F, Figarella-Branger D, Martin PM, Ouafik L: Targeting adrenomedullin receptors with systemic delivery of neutralizing antibodies inhibits tumor angiogenesis and suppresses growth of human tumor xenografts in mice. FASEB J 2009, 23:3424-3435

31. Chen P, Huang Y, Bong R, Ding Y, Song N, Wang X, Song X, Luo Y: Tumor-associated macrophages promote angiogenesis and melanoma growth via adrenomedullin in a paracrine and autocrine manner. Clin Cancer Res 2011, 17:7230-7239

32. Nishimatsu H, Hirata Y, Shindo T, Kurihara H, Kakoki M, Nagata D, Hayakawa H, Satonaka H, Sata M, Tojo A, Suzuki E, Kangawa K,
Matsuo H, Kitamura T, Nagai R: Role of endogenous adrenomedullin in the regulation of vascular tone and ischemic renal injury: studies on transgenic/knockout mice of adrenomedullin gene. Circ Res 2002, 90: $657-663$

33. Nishimatsu H, Hirata $Y$, Shindo T, Kurihara H, Suzuki E, Sata M, Satonaka H, Takeda R, Nagata D, Kakoki M, Hayakawa H, Kangawa K, Matsuo H, Kitamura T, Nagai R: Endothelial responses of the aorta from adrenomedullin transgenic mice and knockout mice. Hypertens Res 2003, 26(Suppl):S79-S84

34. Miyashita K, Itoh H, Sawada N, Fukunaga Y, Sone M, Yamahara K, Yurugi-Kobayashi T, Park K, Nakao K: Adrenomedullin provokes endothelial Akt activation and promotes vascular regeneration both in vitro and in vivo. FEBS Lett 2003, 544:86-92

35. Hellstrom M, Phng LK, Hofmann JJ, Wallgard E, Coultas L, Lindblom P, Alva J, Nilsson AK, Karlsson L, Gaiano N, Yoon K, Rossant J, Iruela-Arispe ML, Kalen M, Gerhardt H, Betsholtz C: Dl14 signalling through Notch1 regulates formation of tip cells during angiogenesis. Nature 2007, 445:776-780

36. Lobov IB, Renard RA, Papadopoulos N, Gale NW, Thurston G, Yancopoulos GD, Wiegand SJ: Delta-like ligand 4 (Dl14) is induced by VEGF as a negative regulator of angiogenic sprouting. Proc Natl Acad Sci U S A 2007, 104:3219-3224

37. Yurugi-Kobayashi T, Itoh H, Schroeder T, Nakano A, Narazaki G, Kita F, Yanagi K, Hiraoka-Kanie M, Inoue E, Ara T, Nagasawa T, Just U, Nakao K, Nishikawa S, Yamashita JK: Adrenomedullin/cyclic AMP pathway induces Notch activation and differentiation of arterial endothelial cells from vascular progenitors. Arterioscler Thromb Vasc Biol 2006, 26:1977-1984

38. Yuda $\mathrm{K}$, Takahashi $\mathrm{H}$, Inoue $\mathrm{T}$, Ueta $\mathrm{T}$, Iriyama $\mathrm{A}$, Kadonosono $\mathrm{K}$, Tamaki Y, Aburatani H, Nagai R, Yanagi Y: Adrenomedullin inhibits choroidal neovascularization via CCL2 in the retinal pigment epithelium. Am J Pathol 2012, 181:1464-1472

39. Yanagawa B, Kataoka M, Ohnishi S, Kodama M, Tanaka K, Miyahara Y, Ishibashi-Ueda H, Aizawa Y, Kangawa K, Nagaya N: Infusion of adrenomedullin improves acute myocarditis via attenuation of myocardial inflammation and edema. Cardiovasc Res 2007, 76:110-118 